\title{
UNA APROXIMACIÓN A LA ACCESIBILIDAD TURÍSTICA. POR UN TURISMO PARA TODOS
}

\author{
Manuela del Pilar Santos Pita ${ }^{1}$ \\ Universidade da Coruña
}

\begin{abstract}
Resumen: El ocio y las vacaciones constituyen un derecho para todos pero, a pesar de ello, poco más de la mitad de la población europea está en condiciones de poder ejercer plenamente ese derecho lo que es debido a diferentes circunstancias. Las incapacidades invalidantes, las discapacidades, ya sean temporales o permanentes, o el envejecimiento de la población, provoca un aumento del número de personas que requieren cuidados especiales y atenciones particulares. La idea de un turismo para todos responde a fundamentos de carácter ético, lo que produce una cualificación de los destinos turísticos así como una mayor humanización. No obstante no se puede obviar su enorme magnitud en términos de mercado, lo que obliga a las instituciones a facilitar la eliminación de barreras tanto físicas, como culturales o sociales que impiden el pleno aprovechamiento por todos de los recursos turísticos.

La primera referencia a lo que habría de ser un "turismo accesible" viene dada por la Organización Mundial del Turismo redactó que en la llamada Declaración de Manila (1980) en la que se mostraba una clara preocupación por eliminar todo tipo de discriminación en las relaciones turísticas, mostrando pues una tendencia hacia la idea de lo que habría de ser el turismo accesible a todas las personas. A partir de ahí se inicia un recorrido cuyo fin no es otro que todos podamos participar de las actividades turísticas en situación de igualdad.
\end{abstract}

Palabras clave: Turismo, igualdad, discapacidad, accesibilidad, diseño para todos.

\section{Resumo: Unha aproximación á accesibilidade turística. Por un turismo para todos}

O ocio e as vacacións constitúen un dereito para todas as persoas, mais a pesar disto pouco máis da metade da poboación europea está en condicións de poder exercelo plenamente, o que é debido a diferentes circunstancias. As minusvalías de calquera tipo, sexan temporais ou permanentes, ou o envellecemento da poboación provocan un aumento do número de persoas que requiren coidados especiais e atencións particulares. A idea dun turismo para todos responde a fundamentos de carácter ético, o que motiva unha cualificación dos destinos turísticos así como unha maior humanización. Porén, non pode obviarse a súa enorme magnitude en termos de mercado, o que obriga as institucións a facilitaren a eliminación das barreiras tanto físicas como culturais ou sociais que impiden o pleno aproveitamento por todas as persoas dos recursos turísticos.

A primeira referencia ao que habería de ser un turismo accesible vén dada pola Organización Mundial do Turismo, que na chamada Declaración de Manila (1980) se manifestaba claramente preocupada por eliminar calquera tipo de discriminación nas relacións turísticas, e amosaba

1 mpsantos@udc.es 
deste xeito unha tendencia cara á idea do que habería de ser o turismo accesible a todas as persoas. A partir de aí iníciase un percorrido cuxo fin non é senón o de que todos poidamos participar das actividades turísticas en situación de igualdade.

Palabras clave: turismo, igualdade, minusvalía, accesibilidade, deseño para todos.

\begin{abstract}
An approach to tourism and accessibility. For tourism for everybody.
Leisure and holidays constitute a right for everybody but, despite this, little more than half the European population are in a position fully to exercise that right, due to different circumstances. Incapacities, disabilities, whether temporary or permanent, or ageing of the population lead to an increase in the number of people who require special treatment and particular attention. The idea of tourism for everybody responds to ethical fundamentals, which lead to a qualification of tourism destinations as well as greater humanisation. However, we cannot avoid their enormous magnitude in terms of the market, which forces institutions to facilitate the elimination of physical, cultural or social barriers which impede full use of all tourism resources.

The first reference to what would be known as "accessible tourism" was made by the World Tourism Organisation, which in the so-called Manila Declaration (1980) showed a clear concern for eliminating all types of discrimination in tourism relations, thus showing a tendency towards the idea of what would become accessible tourism for everybody. That was the start of a journey which aims to end in a situation in which we can all participate in tourism activities on terms of equality.
\end{abstract}

Key words: tourism, equality, disability, accessibility, design for everyone.

\title{
INTRODUCCIÓN
}

El ordenamiento jurídico español carece de una regulación específica sobre turismo accesible. No obstante existe una abundante normativa sectorial -legislación turística, discapacidad, urbanismo, transportes- que hace expresa referencia a la accesibilidad de las personas que padecen algún tipo de discapacidad como una exigencia ineludible para que los principios de igualdad de trato y la no discriminación sean eficaces. Casi todas ellas recogen preceptos que garantizan en mayor o menor medida, la accesibilidad en las ciudades, las edificaciones, el transporte y la comunicación. En cualquier caso y pese, como decimos, a esa ausencia de regulación específica, se hace preciso encontrar conexiones en las diferentes normativas a fin de poder sentar las bases de la regulación del turismo aplicado a las personas discapacitadas.

En la actualidad y en el ámbito internacional de las Naciones Unidas asistimos a un nuevo enfoque del tratamiento de las personas con discapacidad, pasando de un modelo rehabilitador excesivamente proteccionista a un modelo social, con una evolución al considerar a la persona con discapacidad como un inequívoco sujeto de derechos humanos, olvidando así la antigua percepción del discapacitado como un simple objeto de programas asistenciales a una perspectiva más integradora. Todo ello deriva del reconocimiento de los principios de igualdad y no discriminación.

En nuestra legislación, la Constitución española de 1978 en su artículo 49, encomienda a los poderes públicos "la realización de una política de previsión, tratamiento, rehabilitación e integración de los disminuidos físicos, psíquicos y sensoriales, a los que 
prestarán la atención específica que requieran y a los que ampararán especialmente para el disfrute de los derechos que la Constitución otorga a todos los ciudadanos". Por su parte, el párrafo 2 del artículo 9 establece que “corresponde a los poderes públicos promover las condiciones para que la libertad y la igualdad de las personas sean reales y efectivas, removiendo los obstáculos que impidan o dificulten su plenitud y facilitando su participación en la vida política, cultural y social". En la misma línea el artículo 10, al hacer relación a los derechos y deberes fundamentales, establece "la dignidad de la persona como fundamento del orden político y de la paz social". En congruencia con ello la Constitución española ordena a los poderes públicos -en su artículo 49 y al referirse a las personas con discapacidad- que presten la atención especializada que requieran y el amparo especial para el disfrute de sus derechos. Derechos éstos que guardan íntima conexión con el renombrado Principio de igualdad, recogido en nuestra Constitución en su artículo 14, que viene a reconocer la igualdad ante la ley, sin que pueda prevalecer discriminación alguna .

Pero no es al Estado a quien corresponde la competencia para legislar en aquellas materias que guardan relación con los servicios sociales o la asistencia social y así se recoge en el capítulo III, del título I que al establecer los Principios rectores de la política social y económica del Estado, dispone que "las Comunidades Autónomas asumen de manera exclusiva las competencias en materia de servicios sociales y asistencia social".

Pues bien, en ese disfrute de derechos en régimen de igualdad se incluye algo tan fundamental como es el ocio, del que sin lugar a dudas forma una parte muy importante el turismo.

La nueva vertebración territorial derivada de la Constitución Española de 1978 ha supuesto un cambio sustancial al atribuir a las Comunidades Autónomas las competencias en materia de turismo, lo que se ha llevado a cabo a través de sus Estatutos, de tal manera que en casi todas ellas existe su propia Ley de Turismo, así como Normas Reglamentarias de Desarrollo, lo que ha venido a suponer la no aplicación de las normas estatales, que pese a su antigüedad tienen un carácter supletorio.

\section{EL TURISMO ACCESIBLE. TURISMO PARA TODOS FRENTE A TURISMO PARA DISCAPACITADOS}

"El turismo accesible" existe cuando las formas de transporte, los destinos y los servicios que son ofertados están disponibles y pueden ser utilizados por todos los visitantes. Esa oferta turística ha de venir dada desde una información dirigida a quienes se disponen a realizar los desplazamientos sobre posibles barreras al acceso, así como sobre aquellas medidas apropiadas a fin de ayudar a los turistas a manejarse con ellas en cualquier punto del viaje y en los lugares que ellos elijan visitar. No cabe duda de que los avances tecnológicos, cada vez más presentes en nuestra vida diaria, pueden solucionar muchos de los problemas de autonomía personal que en estos momentos viven las personas con discapacidad severa. La incorporación de estas soluciones tecnológicas a las infraestructuras turísticas mejorarán la calidad de vida del cliente con discapacidad. 
El turismo accesible es un turismo sin barreras y un turismo para todos, con una exigencia de continuidad en el sentido de que la accesibilidad ha de venir dada, como decimos, desde la información por parte de las empresas o agencias que ofrecen servicios turísticos, hasta la vuelta del viaje sin que quepa una solución de continuidad entre el punto de partida y el destino, accesibilidad pues en los desplazamientos, en el urbanismo, en las edificaciones y en los servicios, suponiendo una concatenación de accesibilidades (Fernández, 2004). Así pues, no sirve de nada tener un elemento accesible si para acceder a él nos encontramos con barreras difícilmente franqueables. Implica además la obligatoriedad de que los entornos, productos y servicios hayan de estar concebidos bajo el concepto de diseño para todos. Pero para que se pueda conseguir plenamente la incorporación del principio de diseño para todos, es necesario mejorar la formación en accesibilidad de los agentes implicados en el turismo a diferentes niveles -arquitectos, ingenieros de infraestructuras de transporte, gerentes de hoteles y compañías turísticas, desarrolladores de entornos web, responsable de atención al público, guías y un largo etc.-

Nace el turismo accesible con la finalidad de acercar los destinos turísticos a las personas que padecen algún tipo de discapacidad o limitación. La idea de turismo social está latente en la accesibilidad turística. Se trata de que las personas con necesidades especiales junto con sus acompañantes puedan usar y disfrutar de su tiempo libre en igualdad con aquellos que no padecen tales limitaciones. Ello responde a un enfoque inclusivo, una perspectiva social que supone el reconocimiento de un derecho. Pero no se debe confundir turismo accesible con turismo social. Si el primero de ellos permite que las personas discapacitadas disfruten en las relaciones turísticas en las mismas condiciones que aquellos que no padecen limitaciones, el turismo social se presenta como un concepto mucho más amplio que abarca y va más allá de los elementos físicos que pueden suponer barreras al acceso al turismo.

Turismo accesible por lo tanto nos aparece como equivalente a aquel que facilita el acceso de las personas con discapacidad a las infraestructuras y servicios turísticos, mientras que el turismo social busca facilitar el acceso a las infraestructuras y servicios turísticos a aquellos colectivos de población menos favorecidos. Los potenciales beneficiarios del turismo social son todavía más amplios. Se busca, a través del turismo social que el turismo llegue al mayor grupo posible de personas, a todos los estratos sociales y a las diferentes situaciones económicas, aquellos que tiene una cultura diferente o viven en regiones más desfavorecidas (Marcos y González, 2003).

De la conjunción de la finalidad perseguida a través del turismo accesible y aquella otra que busca el turismo social, nos lleva a la idea de un Turismo para todos. La propia Asamblea de la OMT en su resolución 406 considera que "...el turismo es un derecho abierto por igual a todos los habitantes de nuestro planeta (...) y no se pondrá obstáculo alguno". Pero ya la propia Declaración de Manila afirmó que el turismo moderno es el fruto de la política social que llevó al reconocimiento del derecho a las vacaciones anuales pagadas a. los trabajadores de la misma manera que la Declaración Universal de los Derechos del Hombre afirma que todo ser humano tiene derecho al descanso, al tiempo libre, a una limitación de las horas de trabajo y a vacaciones pagadas. 
En los más recientes estudios dedicados a la accesibilidad turística se hace hincapié en el carácter multidisciplinar de la materia. No podría ser de otra forma dado que los dos pilares básicos sobre los que se asienta -esto es, las relaciones turísticas por un lado, y los derechos de las personas con discapacidad por otro-, son materias que hacen referencia a diferentes disciplinas y obedecen a tratamientos desde muy variadas perspectivas. El turismo accesible pues, puede ser analizado desde un punto de vista social, político, jurídico y ético. Desde estos distintos enfoques podríamos hacer a su vez otras diferentes clasificaciones $y$, así la perspectiva jurídica puede ser contemplada a través de un tratamiento jurídico-constitucional, jurídico-administrativo e incluso un tratamiento jurídico-penal.

Si partimos de la concepción del turismo como una manifestación del ocio, el análisis ha de extenderse a ramas tan diferentes como el Derecho, la Economía, la Estética, la Ética, el Marketing, la Pedagogía, la Política, Psicología, Salud y Sociología. Se trata pues de un necesario y complejo análisis en el que la visión multidisciplinar conlleva aportaciones diferentes y muy valiosas en la búsqueda del desarrollo integral de la persona lo que se consigue desde un estudio que va mucho más allá de los temas concretos (Cuenca, 2006). No cabe duda de que podemos hablar de ocio cuando estamos realizando exclusivamente actividades lúdicas, pero actualmente se tiende también a asociar el ocio con otro aspecto diferente del estrictamente lúdico (Monteagudo, 2007). El ocio puede ser disfrutado igualmente además, a través de experiencias y vivencias solidarias. Tradicionalmente se ha hablado del ocio digno otium cum dignitate.

\section{EL TURISMO ACCESIBLE, UN NUEVO SEGMENTO DE MERCADO}

\section{La Encuesta de Discapacidad, Autonomía personal y situaciones de Dependencia} (EDAD) del Instituto Nacional de Estadística del año 2008 nos dice que el número total de personas residentes en hogares españoles que declaran tener alguna discapacidad asciende a 3.847 .900 , lo que supone un $8,5 \%$ de la población. Pese a que la tasa de discapacidad ha bajado con respecto al último estudio realizado por el INE en el año 1999 -el crecimiento ha sido menor que el total de la población- el número de personas con discapacidad ha crecido en 320.000. En España hay casi 4 millones de discapacitados, de los cuales el $36 \%$ no puede valerse por si mismo, según el INE. La Comunidad Autónoma gallega posee la tasa más elevada de toda España, con un 11,3\% de la población.

Si el turismo accesible aparece como un claro exponente del turismo social, y como una también clara manifestación del derecho al ocio, la opinión actual considera mayoritariamente que podría y puede ser un evidente factor de crecimiento económico. Dadas las importantes infraestructuras turísticas con las que contamos en nuestro país y dado el grave problema de la estacionalización, la promoción del turismo accesible como nuevo nicho de mercado ha sido y está siendo vista en la actualidad desde las opiniones de los estudiosos en la materia, como un mecanismo de actuación capaz de provocar un efecto dinamizador sobre las localidades, tanto directa como indirectamente, de la misma manera que puede contribuir a un reparto equilibrado de las rentas que se gene- 
ran al afectar a otros sectores de la actividad económica (más consumo farmacéutico, más asistencia médica...) (Delgado, 2004).

No cabe duda pues, a la vista de los datos, de que el potencial que suponen las personas con movilidad reducida necesita una respuesta por parte del sector turístico. A través del turismo accesible se extraen más beneficios que con cualquier otra política social, dado que la inversión en infraestructuras turísticas puede ser recuperada por la administración a través de los impuestos. Constituye además un impacto muy favorable para mantener el empleo directo en temporada baja, lo que reduce la acusada estacionalidad propia del sector a la que antes hemos aludido.

Pero no hemos de olvidar que la Organización Mundial del Turismo en su Resolución denominada "Hacia un Turismo Accesible para Todos" incluye en su definición de persona con discapacidad a efectos del turismo a las personas mayores. Cuando nos centramos en el análisis del Turismo accesible desde la perspectiva de los beneficios económicos que puede generar no podemos olvidar que en él está latente la idea del turismo para todos, a fin de que todos podamos acceder a los elementos y servicios turísticos. A estos efectos en España desde el IMSERSO se vienen desarrollando programas sociales de vacaciones destinados a los mayores, con los objetivos de facilitar la incorporación de este colectivo a las corrientes turísticas, al tiempo que paliar las consecuencias que en materia de empleo produce la ya renombrada estacionalidad del sector turístico.

\section{LA ACCESIBILIDAD COMO UNA MANIFESTACIÓN DE LA CALIDAD TURÍSTICA}

En el tratamiento que de la accesibilidad hacen los diferentes autores hay una clara coincidencia en considerarla como un elemento más de la calidad en el producto turístico. Dado que en España la primera industria es el turismo no cabe duda alguna de que la promoción de una buena imagen de nuestro turismo va a redundar en unos mejores beneficios económicos. Y la imagen de un servicio turístico accesible o de un entorno accesible para todos supone una mayor calidad turística. Calidad turística que guarda relación por un lado con el aspecto social y de preocupación medioambiental del turismo y por otro el aspecto relativo a la repercusión económica del sector turístico. Se hace necesario en la búsqueda de una mejora en la calidad turística que la oferta de entornos y servicios turísticos llegue al mayor número posible de personas y que se haga de una manera integral y coordinada. No caben pues compartimentos estancos. Quizás conviene preguntarse si la accesibilidad como elemento de calidad viene a representar un presupuesto para la continuidad y la evolución del sector, o bien, si la calidad derivada de la accesibilidad viene dada más que por la repercusión en los beneficios económicos, ésto es, como generadora de un rendimiento económico o como un reconocimiento de los derechos, pudiendo decir así que la accesibilidad en el sector turístico supone un avance en la calidad de vida de la sociedad, dado que significa una correcta prestación de determinados servicios. Y para que esta calidad sea real y efectiva, la formación de los profesionales del sector es fundamental. 
Pues bien, en la nueva Ley de turismo de Galicia, de 3 de diciembre de 2008 se recoge expresamente en su art. 10,2 la calidad de los bienes y servicios como un derecho de los usuarios turísticos. Pero es en su artículo 16 donde define esa calidad al contemplar la obligación de la Administración turística gallega de velar por la calidad de los servicios, lo que se concreta en acciones como "corregir las deficiencias de infraestructuras, instalaciones y los equipamientos turísticos", "corregir un trato adecuado en la prestación", "facilitar una mayor profesionalización de las personas que trabajen en el sector, así como su acceso a una mayor formación continua" $\mathrm{y}$, finalmente como una cláusula abierta : "en general, cualquier acción pública o de apoyo de la iniciativa privada dirigida a obtener la excelencia en la prestación de las actividades turísticas".

\section{LA PREOCUPACIÓN INTERNACIONAL POR EL TURISMO PARA TODOS}

Existe en el ámbito internacional una enorme sensibilidad en torno al principio de igualdad de todas las personas y la no discriminación. Tanto la Organización de Naciones Unidas, ONU, como diferentes organismos internacionales muestran su enorme preocupación por los derechos de los discapacitados. Y esa preocupación viene dada por la necesidad de abandonar la vieja tendencia protectora con respecto a las personas discapacitadas por una más actual integradora, consistente en tomar a estas personas como titulares de los mismos derechos que los demás pero con unas especiales dificultades para desarrollar las actividades diarias. De igual manera que se tiende al general reconocimiento de que a estas dificultades personales hay que añadirles las que les vienen dadas por el entorno.

La evolución vivida durante los últimos años en materia accesibilidad ha sido importante, habiendo dejado atrás el antiguo concepto de eliminación de barreras arquitectónicas para acuñar el término de accesibilidad universal. Han sido muy importantes los documentos adoptados por los diversos organismos que tienen especial relevancia en el mundo del turismo. En esta línea en el mes de agosto de 2006, la Convención de la ONU sobre Derechos de las Personas con Discapacidad que tuvo lugar en Nueva York, en la sede de las Naciones Unidas aprobó un Tratado Internacional por el que se garantizan los derechos y libertades de los discapacitados, constituyendo el primer Tratado sobre derechos humanos que se aprueba en el siglo XXI, lo que sin duda habrá de conllevar una clara mejora desde el punto de vista práctico en el tratamiento de las personas con discapacidad. La búsqueda por la eliminación de una serie de habituales prácticas evidentemente discriminatorias está presente en el espíritu de este Convenio. Se trata ante todo de cambiar el matiz de protección y asistencia por el de igualdad y participación, pero para ello es fundamental un cambio de actitud a fin de que los discapacitados puedan aparecer en la vida social en un plano de igualdad con el resto de las personas, porque lo que en principio pudiera ser algo incuestionable por cualquier país no lo ha sido así para Estados Unidos que decidió no firmar el tratado argumentando que su legislación sobre el tema es suficiente, lo que no viene más que a demostrar que pese a los intentos queda todavía mucho que hacer sobre el tema. Corresponderá pues, a los países 
que lo ratifiquen la labor de lucha porque igualdad y la no discriminación habrán de ser efectivas. Además los procesos de normalización y certificación están tomando importancia en diversos países de la Unión Europea lo que supone la adopción de estándares y la evaluación de las condiciones de accesibilidad por entidades especialistas en esta materia. Sin duda alguna este avance es tremendamente positivo de modo que los clientes con necesidades diferentes a las convencionales puedan planificar sus viajes con garantías de éxito. Pero es quizás la sensibilización una de las líneas fundamentales de actuación en las políticas internacionales.

Y ya desde las instituciones de la Unión Europea se reconoce el derecho de todas las personas a la igualdad ante la ley, así como la protección contra la discriminación lo que se recoge en la Carta Europea de los Derechos Fundamentales así como en el Convenio Europeo para la protección de los Derechos Humanos y de las Libertades Fundamentales. El artículo 13 del Tratado constitutivo de la Comunidad Europea habilita al Consejo para adoptar acciones adecuadas para luchar contra la discriminación por motivos de sexo, de origen racial o étnico, religión o convicciones, discapacidad, edad o condición sexual.

En el año 1974 ya se había aprobado el primer programa europeo dirigido específicamente a las personas con discapacidad, que sirvió para establecer los pilares de lo que sería el nacimiento de una política social comunitaria en materia de discapacidad, es el Programa de acción comunitaria para la readaptación profesional de los minusválidos. En él se muestra una clara preocupación por la integración social de este colectivo de personas, haciendo hincapié en su derecho al trabajo en nivel de igualdad con el resto de los ciudadanos. Con este programa se busca el fomentar la independencia y la plena integración de las personas con discapacidad. En él se ofrece el compromiso de ayuda por parte de las instituciones europeas, con la finalidad de conseguir que su vida sea una vida igual a la de cualquier otra persona, totalmente normal, y establece de igual manera que el camino fundamental para la consecución de la igualdad es la promoción de la capacidad de trabajo.

En la década de los 80 se comienza a prestar una especial atención por parte de las instituciones a todos aquellos temas relacionados con los derechos de los discapacitados. Es a partir de entonces cuando comienza a realizarse un prolijo trabajo de investigación y de creación de directrices sobre el tema ${ }^{2}$. En 1988 se pone en marcha el segundo programa de acción de la Comunidad en favor de los minusválidos (HELIOS), que se aplicaría durante el cuatrienio 1988/1991. Con él se constituye una plataforma dirigida a

2 Así la Resolución del Parlamento Europeo sobre la integración económica, social y profesional de los minusválidos en la Comunidad, de 11 de mayo de 1981, coincidiendo con el Año Internacional de las Personas con Discapacidad; Comunicación de la Comisión sobre líneas directrices de una acción comunitaria para la inserción social de los minusválidos, de 4 de noviembre de 1981; Resolución del Consejo y de los representantes de los Estados miembros reunidos en la sede del Consejo sobre la integración social de los minusválidos, de 21 de julio de 1986; Resolución del Parlamento Europeo sobre el transporte de minusválidos y ancianos de 16 de septiembre de 1986; Conclusiones relativas a un programas de colaboración europea sobre la integración de los niños disminuidos en escuelas ordinarias, de 14 de mayo de 1987; Resolución del Parlamento Europeo sobre lenguajes gestuales para sordos, de 17 de junio de 1988. 
fomentar la cooperación entre los Estados miembros así como los intercambios en temas como la integración económica y social, la igualdad de oportunidades y la vida independiente de las personas con discapacidad. Pretendía la plataforma fundamentar las actuaciones en la formación, y la rehabilitación profesional, así como la integración económica y social y el fomento de la autonomía de los minusválidos.

Posteriormente, en el año 1993, el Consejo aprobó a través de la Decisión de 25 de febrero de 1993, el tercer programa de acción comunitaria para las personas minusválidas, para el cuatrienio 1993/1996, lo que significaba una continuación de las acciones ya iniciadas dentro del programa HELIOS. La dotación presupuestaria de tal programa trata de conseguir una mayor efectividad -de hecho duplicaba el presupuesto anterior-. Y no solamente se limita a una ampliación presupuestaria sino que los objetivos se amplían llegando a abordarse temas que resultaban innovadores y se profundiza en aquellos que ya habían sido considerados de importancia. Se muestra una especial preocupación en temas tales como la integración en la educación, la formación profesional, la readaptación funcional, la integración económica y social y la mejora de la autonomía. Con un especial interés se potencia la intervención de los interlocutores sociales, dando especial protagonismo a Organizaciones No Gubernamentales, a través del Foro Europeo de la Discapacidad, que se constituye como un marco permanente de participación de las personas con discapacidad y de sus familias, a través de las organizaciones que lo agrupan.

En 1996, la muy valiosa experiencia de los sucesivos programas HELIOS determina la aparición de la Comunicación sobre la igualdad de oportunidades de las personas con minusvalía, adoptada por la Comisión Europea el 30 de julio, que viene a definir la estrategia de la Unión Europea con respecto a la discapacidad, incardinándola en la evolución de las tendencias internacionales de los últimos años. Propugna la Comunicación un enfoque basado en las ideas de igualdad de oportunidades, no discriminación, derechos, normalización, inclusión y plena participación, y respalda los planteamientos recogidos en las Normas uniformes sobre igualdad de oportunidades para las personas con discapacidad (1993), elaboradas por las Naciones Unidas sobre la base de la experiencia adquirida a lo largo del Decenio de las personas con discapacidad, y en la recomendación del Consejo de Europa sobre una Una política coherente para la integración de las personas con minusvalía (1992), primando la integración, por encima del objetivo más limitado de la adaptación, como el factor fundamental para permitir la inserción de las personas con discapacidad en la sociedad activa.

Pues bien, la Comisión pretende integrar los asuntos relativos a la discapacidad en las políticas generales de la Comunidad (mainstreaming), y lo hace utilizando una estrategia de la cooperación y diálogo político con los Estados miembros. Se plantea la necesidad de revisar las políticas nacionales, así como la búsqueda de información a través de las diferentes experiencias, lo que se realiza a través del Grupo de Alto Nivel sobre Discapacidad (High Level Group on Disability) que da un mayor impulso al diálogo social tanto con los propios agentes sociales como de estos entre sí, dando, como ya queda dicho una especial preponderancia al trabajo de las ONG. La participación de los distintos interlocutores sociales no exime de la principal obligación de los Estados apor- 
tando un valor añadido significativo en el proceso de reflexión y acción con y entre los Estados miembros.

\section{ASPECTOS JURÍDICO NORMATIVOS DE LA ACCESIBILIDAD TURÍSTICA EN EL DERECHO ESPAÑOL. ESPECIAL REFERENCIA A LA COMUNIDAD AUTÓNOMA GALLEGA}

En España, en el año 2003 habían pasado veinte años desde la promulgación de la Ley de Integración Social de los Minusválidos (LISMI) y se hacía precisa una renovación sin que ello supusiera una separación del espíritu que en su momento había inspirado al legislador. Ni que decir tiene que pese a los intentos de la ley por la equiparación de las personas con discapacidad, seguían existiendo desigualdades - no en vano se realizó un enorme esfuerzo por modificar los enfoques y las estrategias en las políticas de equiparación de las personas con discapacidad.

La Ley de Igualdad de Oportunidades y Accesibilidad Universal de las Personas con Discapacidad (LIONDAU) aprobada por la Cortes Generales por unanimidad de todos los grupos políticos y sin alegaciones en contra de ninguna Comunidad Autónoma, pone de manifiesto el consenso existente y la necesidad de un nuevo planteamiento de la accesibilidad, que a partir de entonces cobra un nuevo carácter, dejando de ser considerada como un aspecto más o menos intenso de la acción social o los servicios sociales, para ser entendida como un presupuesto esencial para el ejercicio de los derechos fundamentales que asisten a los ciudadanos con discapacidad. Para ello, la ley establece en su disposición final novena que "el Gobierno aprobará, en el plazo de dos años desde la entrada en vigor de esta Ley, según lo previsto en su artículo 10, unas condiciones básicas de accesibilidad y no discriminación para el acceso y utilización de los espacios públicos urbanizados y las edificaciones". Y se hacía necesario pues, el diseñar una serie de líneas de actuación que pudiesen operar sobre las condiciones personales pero también sobre aquellas condiciones ambientales que la propia sociedad transforma en barreras impidiendo la plena integración de estos ciudadanos. La Ley de igualdad de oportunidades y accesibilidad universal de las personas con discapacidad recoge dos diferentes estrategias de intervención que operan simultáneamente, por un lado la "lucha contra la discriminación" -a fin de conseguir la igualdad de trato así como la igualdad de oportunidades- y por otro la "accesibilidad universal". Reconoce por lo tanto, como decimos, la norma que siguen existiendo desigualdades, pero además, y dado el tiempo transcurrido, ya no solamente es la existencia de desigualdades el objetivo de lucha, sino que además la evolución de la sociedad ha provocado también diferentes formas de concebir las discapacidades y, consecuentemente, la aparición de nuevos enfoques y estrategias.

Un importante y nuevo enfoque que se da a la discapacidad es el hecho de admitir que las limitaciones derivan ya no solamente de la misma persona sino también de los obstáculos que la propia sociedad "concebida conforme al modelo de persona media" le impone. Es a partir de entonces cuando se toma la determinación de adoptar políticas que 
impliquen estrategias que actúen tanto sobre las condiciones personales como sobre las condiciones sociales y ambientales.

El año de aprobación de la LIONDAU en España coincide con la celebración del Año Europeo de las Personas con Discapacidad, constituyendo, de esta manera una auténtica aportación de nuestro país a las políticas y los objetivos de la Unión. Las exigencias de la LIONDAU en torno a la necesidad de una normativa estatal específica sobre accesibilidad han encontrado su respuesta con el Real Decreto 505/2007, de 20 de abril, por el que se aprueban las condiciones básicas de accesibilidad y no discriminación de las personas con discapacidad para el acceso y utilización de los espacios públicos urbanizados y edificaciones. Pues bien, el Real Decreto 505/2007, de 20 de abril, por el que se aprueban las condiciones básicas de accesibilidad y no discriminación de las personas con discapacidad para el Acceso y utilización de los espacios públicos urbanizados y edificaciones viene a regular las condiciones básicas recogidas en la ley garantizando así a quienes presentan alguna discapacidad una efectiva igualdad de oportunidades y la no discriminación. Se trata además, de unificar criterios y armonizar las diferentes normas de las Comunidades Autónomas o de los entes dotados de competencia en cuestiones de accesibilidad a fin de, como queda dicho, evitar los desequilibrios. La normativa utiliza una visión de la accesibilidad basada en el diseño para todos, la autonomía personal, asumiendo la existencia innegable de la pluralidad dentro de la discapacidad.

Es importante señalar que la norma ha sido consensuada, al igual que lo fue la LIONDAU. En su elaboración han intervenido diferentes agentes, el Consejo Nacional de Discapacidad, por medio de informes o consultas. Además, el proyecto ha sido sometido a audiencia de las entidades que representan a los ciudadanos afectados por el mismo y cuyos fines guardan relación con su objeto. De igual modo, han sido consultadas las Comunidades Autónomas, a través de la Comisión Multilateral de Vivienda y de la Conferencia Sectorial de Asuntos Sociales. Las exigencias básicas en lo relativo a la edificación vienen recogidas en la norma en su Disposición Final Tercera, "Incorporación de las condiciones básicas de accesibilidad y no discriminación para el acceso y utilización de los edificios al Código Técnico de la Edificación”. En lo relativo a la edificación el Real Decreto recoge la obligación de que el Código Técnico de la Edificación (aprobado por el Real Decreto 314/2006, de 17 de marzo) y al menos con un año de antelación a la fecha en que se establece la obligatoriedad de la norma para los edificios nuevos (disposición final quinta de la ley), habrán de ser incorporadas al mencionado Código Técnico de la Edificación las condiciones básicas de accesibilidad y no discriminación para el acceso y utilización de los edificios.

La norma recoge también en su Disposición final cuarta, las exigencias de accesibilidad y no discriminación para el acceso y utilización de los espacios públicos urbanizados y contempla también el plazo de un año de antelación a la fecha que la propia norma establece para los espacios públicos nuevos, las condiciones básicas de accesibilidad y no discriminación para el acceso y la utilización de los espacios públicos urbanizados que se aprueban en virtud del presente real decreto se desarrollarán en un documento técnico que se aprobará por orden del Ministerio de Vivienda. Fija el 
Real Decreto la fecha del 1 de enero de 2010, para iniciar la obligatoriedad de estas condiciones básicas de accesibilidad y no discriminación para el acceso y utilización de los espacios públicos urbanizados y edificaciones que se aprueban en virtud del presente real decreto, que serán obligatorias para los espacios públicos urbanizados nuevos y para los edificios nuevos, así como para las obras de ampliación, modificación, reforma o rehabilitación que se realicen en los edificios existentes, y a partir del día 1 de enero de 2019 para todos aquellos espacios públicos urbanizados y edificios existentes que sean susceptibles de ajustes razonables. Exceptúa la norma las oficinas de atención al ciudadano que se rigen por su normativa específica y de acuerdo con lo dispuesto en la LIONDAU.

La actual estructura organizativa del turismo ha de analizarse desde la evolución acaecida en los últimos 20 años. Esta evolución ha tenido como fundamento un espíritu diferente y una filosofía muy distinta que afecta sin lugar a dudas a los esquemas competenciales. Se sustituye el anterior modelo economicista y ante todo cuantitativo por otro más cualitativo, para el que el fin económico viene unido a otros fines diferentes y colaterales. Como es de esperar este cambio de criterio habría de afectar a la estructura organizativa del turismo. No hay que olvidar los cambios acaecidos en las propias estructuras de poder en España, donde se ha producido un espectacular desapoderamiento de la Administración Estatal para dar un mayor protagonismo a las Administraciones autonómicas y locales. Pero son las diferentes Administraciones autonómicas las que han resultado más beneficiadas en este cambio en la estructura organizativa del Turismo en España, tanto que las propias Administraciones locales han visto reducido su ámbito de poder. No hay que dejar de tener en cuenta que el desarrollo de la materia turística es eminentemente local. Así, no solamente el fenómeno del desapoderamiento de la Administración estatal ha provocado los cambios en la estructura organizativa del Turismo sino que la tendencia a una mayor preocupación por la calidad del fenómeno turístico ha tenido en ella un claro reflejo.

De todos es conocido que los objetivos perseguidos en la reglamentación turística son cada vez mayores, ello provoca que las estructuras organizativas hayan de acomodarse a los diferentes fines perseguidos, apareciendo así nuevas estructuras organizativas. Los cambios adoptados por la política turística han sido esencialmente cualitativos. Las estructuras de nueva creación se mueven principalmente en el campo de la intervención. Este campo es en el que con mayor intensidad se va a reflejar la dialéctica entre las diferentes fórmulas de gestión, fórmulas que se mueven tanto dentro del ámbito público como del privado. Pero no hay que obviar que los cambios obedecen también a los profundos avances tecnológicos que tiene lugar en los últimos años. Ese desarrollo tecnológico va a influir profundamente en las técnicas organizativas de programación y planificación.

En los años ochenta se inicia una labor normativa sobre accesibilidad y se hace tanto desde el ámbito normativo estatal como en los diferentes marcos autonómicos. Es misión de los poderes públicos el velar porque las personas con discapacidad puedan disfrutar plenamente de sus derechos tanto civiles, como económicos, sociales o culturales. 
Ya en la LISMI se recogen una serie de medidas tendentes a facilitar la movilidad y accesibilidad de este grupo social, a cuyo fin las administraciones públicas competentes debían aprobar las normas urbanísticas y arquitectónicas básicas. Pasados más de veinte años desde la promulgación de la LISMI el marco normativo se encontraba bastante disperso, la existencia de diferentes Leyes y Reglamentos de ámbito autonómico derivado de la competencia de los entes autonómicos para establecer normas en este ámbito. Faltaba pues, una norma que sirviese de presupuesto unificador, lo que fue provocando que las interpretaciones en la aplicación de la norma fuesen también muy variadas, lo que inevitablemente podía provocar situaciones discriminatorias o de desigualdad. Por eso la LIONDAU viene a ser una claro reflejo del consenso existente en la configuración de la accesibilidad, que pasa a ser entendida como un requisito esencial para el ejercicio de los derechos de las personas que padeciesen algún tipo de discapacidad.

Además la Ley 49/2007, de 26 de diciembre, por la que se establece el régimen de infracciones y sanciones en materia de igualdad de oportunidades, no discriminación y accesibilidad universal de las personas con discapacidad, viene a constituir un sistema de arbitraje para la resolución de aquellas quejas presentadas por personas que padezcan algún tipo de discapacidad, es por lo tanto, un sistema de resolución de conflictos de forma extrajudicial. A tal efecto se constituye la Junta Arbitral Central a fin de resolver aquellas quejas que afecten al ámbito superior de una Comunidad Autónoma. No obstante en cada una de ellas se constituirán Juntas Arbitrales, siendo estos árbitros propuestos por la Administración, las asociaciones más representativas de personas con discapacidad y sus familias y las organizaciones de carácter económico sin ánimo de lucro, debiendo ser los árbitros expertos o profesionales en algunas de las materias sobre las que puedan versar las quejas o bien licenciados en Derecho. Por lo que respecta al laudo arbitral, el plazo máximo para dictarlo es de cuatro meses desde el inicio del procedimiento y se prevé la posibilidad de que se dicte laudo conciliatorio si las partes llegan a un acuerdo que resuelva la controversia. La constitución de este sistema de arbitraje viene a dar respuesta a históricas peticiones de las personas con discapacidad.

En la Comunidad Autónoma Gallega el Decreto 286/1992, de 8 de octubre (LG 1992,262) que constituía la norma básica en Galicia viene a ser sustituido por la ley 8/97, de 20 de Agosto, de accesibilidad y supresión de barreras en la Comunidad Autónoma Gallega. Se hacía necesario que la norma tuviese un ámbito de aplicación más extenso y un más extenso ámbito de aplicación y un régimen sancionador más eficaz para hacer frente a las necesidades de las personas con discapacidad. La propia evolución de la sociedad determinada por las necesidades de las personas que la conforman exigía que el urbanismo, los transportes públicos, las comunicaciones en general llegasen y fuesen accesibles a todos. La ley de accesibilidad reconoce que pese a su propias previsiones, es la sensibilización a los profesionales - del urbanismo, arquitectura, industria, deporte y comunicaciones- el elemento fundamental que realmente considera la norma a fin de que las personas con algún tipo de discapacidad puedan disfrutar plenamente de sus 
derechos. Entre sus objetivos se pretende garantizar la accesibilidad, así como la utilización del entorno urbano, los edificios, los medios de transporte y los sistemas de comunicación sensorial, y a tal fin se propone eliminar las barreras existentes.

Creemos que quizás la accesibilidad debería extenderse al entorno natural. En los viajes cuyo fin es disfrutar de la naturaleza, la práctica de actividades al aire libre, como ocurre con el turismo de costa y playa, el turismo rural, incluso el turismo cultural, donde las visitas a los inmuebles que pueden constituir bienes de interés cultural se desarrollan en ocasiones en entornos no urbanizados, en todos ellos como decimos, la accesibilidad se hace ineludible a fin de permitir que todas las personas puedan disfrutar plenamente y sin limitaciones producidas desde el propio entorno. Para ello la norma se propone establecer aquellas medidas de fomento necesarias para conseguir la integración de personas con limitaciones. Y así, para que tales objetivos puedan ser alcanzados se prevé un eficaz control de la aplicación normativa a través de un régimen sancionador para aquellos incumplimientos de la norma. Su aplicación se extiende a las actuaciones de personas jurídico-públicas y jurídico-privadas, así como a las personas individuales que hayan sido llevadas a cabo en la Comunidad Autónoma Gallega en materia de planeamiento, gestión o ejecución urbanística, nueva construcción, rehabilitación o reforma de edificaciones, transporte y comunicación.

La nueva y reciente Ley de Turismo de Galicia (Ley 14/2008, de 3 de diciembre ) reconoce en su título II dedicado a la organización y competencias de la Administración turística gallega como Administraciones competentes en materia de turismo las siguientes: La Administración de la Xunta de Galicia, los ayuntamientos y las entidades locales supramunicipales, así como los organismos autónomos y las entidades de derecho público constituidos por cualquiera de las administraciones indicadas, o adscritos a las mismas, para el ejercicio de las competencias que afecten al sector turístico. Una vez enunciados las diferentes entidades con competencia en materia turística, establece las competencias que corresponden a la Administración autonómica. En esa exhaustiva relación de competencias cabe destacar el apartado f) que recoge expresamente: "El ejercicio de las potestades administrativas de planificación, programación, fomento, inspección y sanción previstas en la presente Ley, de forma exclusiva o en colaboración con otras administraciones". Prevé por tanto la norma en lo relativo al ejercicio de las potestades propias de las competencias turísticas dos formas de actuación. La Administración autonómica actuará con exclusividad en el ejercicio de sus potestades, pero también lo hará en concurrencia con otras administraciones. Además, el artículo quinto de la norma al recoger las competencias propias de los municipios, otorga una serie de atribuciones a estos entes administrativos locales y ello siempre sin perjuicio de lo dispuesto en la legislación de régimen local. Además de sus competencias exclusivas, la nueva norma contempla algo tan importante como es la posibilidad de cooperación con la Administración autonómica instrumentada a través de fórmulas cooperativas idóneas como la consorcial.

El municipio a tenor de lo dispuesto en la norma, puede actuar por delegación de la Administración autonómica pero siempre con el límite legal de la normativa sobre 
régimen local. Contempla la norma además, expresamente las competencias propias de las entidades locales supramunicipales, entes que en la actualidad están logrando una mayor proliferación dada la necesidad de colaboración entre los diferentes agentes implicados en muy diversos sectores, como el turístico. Las competencias de estas entidades de ámbito superior al del municipio habrán de ser ejercidas en coordinación con el departamento correspondiente de la Administración autonómica y con otras administraciones turísticas del ámbito local.

\section{CONCLUSIONES}

Los diferentes agentes que intervienen en el sector turístico, tanto privados como públicos, han empezado, aunque muy lentamente, a tomar conciencia de la importancia de la accesibilidad en los entornos, productos y servicios. Es por ello que se comienzan a tomar iniciativas en el tejido empresarial turístico para poder captar a muchos clientes que cada día son más si se tiene en cuenta el fenómeno del envejecimiento. La sectorialización de las políticas dificulta la aplicabilidad de las normas. Es imprescindible un tratamiento transversal de la accesibilidad. Para la plena eficacia de las normas es precisa la utilización de mecanismos de seguimiento y control a fin de conseguir los objetivos perseguidos. Se hace preciso superar el clásico concepto de «eliminación de barreras arquitectónicas» y apostar por un nuevo modelo cuya finalidad sea garantizar el pleno y libre desarrollo de las personas en el medio social y comunitario y, para ello, garantice la accesibilidad al medio físico y a la comunicación a todas las personas y de una manera especial a aquellas que por razones diversas presenten algún tipo de limitación.

Es quizás la sensibilización la forma más eficaz de conseguir que el turismo pueda ser disfrutado por todos los usuarios en régimen de igualdad y con comodidad. El turismo accesible es un derecho y como tal ha de manifestarse ante el conjunto de la sociedad. Pero esta sensibilización ha de predicarse no solamente de las administraciones públicas sino también de los diferentes agentes privados implicados, los profesionales del sector turístico. Pero no es menos necesaria la sensibilización de la sociedad en general a fin de eliminar estereotipos y barreras sicológicas tan dañinas y contraproducentes.

Las condiciones que se ofrecen a las personas que padecen algún tipo de discapacidad no han de ser diferentes de aquellas que se ofrecen a los demás usuarios de servicios turísticos, siendo para ello el Diseño para Todos una figura especialmente relevante en las políticas urbanísticas y de edificación. Las personas con discapacidad son ciudadanos de pleno derecho, y tienen las mismas expectativas y aspiraciones como ciudadanos que los demás. El turismo supone un bien social vivamente demandado por este colectivo. Son clientes que demandan el acceso a la oferta turística con normalidad, y sin tener que pagar un mayor precio por limitaciones de las infraestructuras. La accesibilidad no ha de ser disfrutada como lujo, sino que ha de hacerse extensiva a todas las economías. La aplicación del Diseño para Todos en la concepción de los productos y servicios turísticos para conseguir la Accesibilidad Universal, supone 
una relevante ventaja competitiva para todos aquellos agentes turísticos que apuesten por esta estrategia. Sabiendo que en los edificios de nueva planta no suponen ningún aumento de coste, y la inversión en las reformas es fácilmente recuperable.

\section{BIBLIOGRAFÍA}

Alcain, Esperanza et al. (2006): Régimen jurídico de las personas con discapacidad en España y en la Unión Europea. Granada. Ed. Comares.

Álvarez, Josefa (1998): “El diseño de productos para personas con discapacidades. El punto de vista de los usuarios" Economía industrial, 324.

Brinckmann, Wanderleia Elisabeth, et al. (2003): "Desafíos para los estudiosos del turismo: la construcción de la "sociedad inclusiva" y del "turismo accesible", Cuadernos de Turismo. $n^{\circ} 11, p p$. 41-58.

Campoy, Ignacio (2004): Los derechos de las personas con discapacidad: perspectivas sociales, políticas, jurídicas y filosóficas. Madrid. Ed. Dykinson

Cuenca, M (2006): “Aproximación multidisciplinar a los estudios de ocio”, Bilbao. Ed. Instituto de Estudios de Ocio. Universidad de Deusto.Bilbao.

Datilo, J (2004): " Servicios de ocio inclusivo", en Ocio, inclusión y discapacidad .Documentos de Estudios de Ocio, núm. 28. Bilbao.

Delgado, José Ignacio (2004): "Reflexiones sobre el turismo accesible" Turismo@Polibea.num.6, Octubre 2004

Egea, Carlos y Sarabia, Alicia (2004): "Visiones y modelos conceptuales de la discapacidad“", Revista Polibea no 73, 2004, ISSN 1137-2192, pp. 29-42. Madrid.

Fernández, Carmen (2003): Derecho administrativo del turismo, Madrid,. Marcial Pons.

Gladwell J. et al. (2004): “" "In search of lost leisure: the impact of caregiving on leisure travel", Tourism Management 25.

Hunter-Jones, Philippa (2004): "Young people, holiday-taking and cancer-an exploratory analysis", Tourism Management 25

Lentini,Biagio et al. (1991): La cittá accesibile. análisi e progetto nel piano per 1,abbatimento delle barriere architectóniche. Firenze. Alinea editrice s.r.l.

López-Guzmán, Tomás et al. (2005): Turismo sostenible: un enfoque multidisciplinar e internacional. Córdoba. Servicio de publicaciones de la Universidad de Córdoba.

Marcos, Daniel y González, Diego (2003): Turismo accesible. Rev. CERMI 2003 Madrid.

Monteagudo, María Jesús (2007): “ El ocio en la investigación actual. una lectura desde ámbitos, disciplinas, grupos de población y contextos geográficos” Bilbao. Universidad de Deusto.

Ozturk, Y, Yaily A, et al. (2007): “ Is the turkish tourism industry ready for a disabled customer's market?the views of hotel and travel agency managers" Tourism management. 
Sanjuanbenito, R et al. (2004): Manual de pautas de calidad de atención para personas con capacidades restringidas, Ed. Fundación Turismo para todos 